This is a preprint of the following chapter: Paasch-Colberg S, Trebbe J, Strippel C, Emmer M: Insults, criminalization, and calls for violence: Forms of hate speech and offensive language in German user comments on immigration, to be published in Cyberhate in the context of migrations by Monnier A, Boursier A, Seoane A (eds.), 2021, Palgrave Macmillan.

\title{
Insults, criminalization, and calls for violence: Forms of hate speech and offensive language in German user comments on immigration
}

\author{
Sünje Paasch-Colberg, Joachim Trebbe, Christian Strippel, and Martin Emmer \\ Institute for Media and Communication Studies, Freie Universität Berlin
}

\begin{abstract}
In the past decade, the public discourse on immigration in Germany has been strongly affected by right-wing populist, racist, and Islamophobic positions. This becomes evident especially in the comment sections of news websites and social media platforms, where user discussions often escalate and trigger hate comments against refugees and immigrants and also against journalists, politicians, and other groups. In view of the threatening consequences such sentiments can have for groups who are targeted by right-wing extremist violence, we take a closer look into such user discussions to gain detailed insights into the various forms of hate speech and offensive language against these groups. Using a modularized framework that goes beyond the common "hate/no-hate" dichotomy in the field, we conducted a structured text annotation of 5,031 user comments posted on German news websites and social media in March 2019. Most of the hate speech we found was directed against refugees and immigrants, while other groups were mostly exposed to various forms of offensive language. In comments containing hate speech, refugees and Muslims were frequently stereotyped as criminals, whereas extreme forms of hate speech, such as calls for violence, were rare in our data. These findings are discussed with a focus on their potential consequences for public discourse on immigration in Germany.
\end{abstract}

Keywords: Content analysis, user comment, hate speech, text annotation, refugees, social media 


\section{Introduction}

In response to increasing cultural diversity in Germany, steady immigration, and especially the admission of refugees from Syria, Afghanistan, and Iraq in 2015 and 2016, conservative and right-wing voices opposing these developments have become louder and more aggressive in the German public over the past decade. These voices have since been well heard at anti-immigration protests (e.g., by the Patriotic Europeans against the Islamization of the Occident [Pegida]), in parliaments (e.g., by the nationalist and populist party, Alternative for Germany [AfD]), mass media, and the Internet. Besides criticizing politics, first and foremost, in the areas of political asylum and European integration (Berbuir, Lewandowsky \& Siri, 2015), these voices are often accompanied by racist and Islamophobic stereotyping, insults, and even threats of violence and murder (Paasch-Colberg, et al., 2021a). This has not only intimidated many people and polarized public discourse (Wegner, Prommer \& Seidel, 2020), but it has also set the stage for a significant increase in right-wing extremist violence against Muslims, People of Color, and public advocates of immigration (Gehrke, 2021), including arson attacks on refugee shelters, rampages (Munich in 2016, Halle in 2019, Hanau in 2020), and assassination attacks on politicians (namely Henriette Reker in 2015, Walter Lübcke in 2019) who publicly supported liberal refugee politics.

The Internet has been a central venue for the broader public discourse on immigration and Islam in Germany in the past years, as it offers right-wing populists a wide range of possibilities to network, organize, and make themselves heard while circumventing the gatekeeping of journalists (Krämer, 2016; Frischlich, Klapprot \& Brinkschulte, 2020). Over time, a right-wing counter public has emerged on alternative news websites, blogs, and forums, such as Compact Online, PI News, and Epoch Times (Puschmann et al., 2016; Bachl, 2018). The comment sections of news websites and social media are particularly important for such right-wing actors, as they reach a 
broad segment of the public on these platforms, where they can promote their positions directly and largely unfiltered (e.g., Toepfl \& Piwoni, 2015; Stier et al., 2020; Rauchfleisch \& Kaiser, 2020). For this reason, these spaces are particularly relevant in the development of the public discourse surrounding immigration as a whole and the severe, threatening consequences it can have for people who are most vulnerable to right-wing violence.

In this chapter, we therefore take a closer look into user discussions on immigration in comment sections of German news websites and social media to analyze hate speech and offensive language against refugees, immigrants, and other target groups in these contexts. In doing so, we aim for a detailed analysis of the incitement and sentiments against these groups in public discourse, relying on a differentiated framework that helps us go beyond the common "hate/no-hate" dichotomy in the field. Using a modularized approach to structured text annotation that allows for the identification of hate speech and offensive language at the sentence level, we seek to contribute to existing research by giving initial insights into the various forms and intensities of hate speech and offensive language against different target groups in German online user comments on refuge and immigration.

To this end, we give some background information about the history of immigration in Germany and present existing research on the media coverage and online discussions about it (Section 2). We then provide a definition of what we consider to be hate speech and discuss the literature on hate speech and offensive language in social media (Section 3). In Section 4, we lay out the framework of our modularized approach to structural text annotation, combining aspects of both quantitative and qualitative content analysis. The findings of our study are presented in Section 5. We close with a discussion of these findings in view of their consequences for public discourse on immigration in Germany and its resultant threats to specific groups. 


\section{Immigration and media in Germany}

In March 2019, the topics of immigration, refuge, and asylum were high on the political and media agenda, both in terms of the long-term and fundamental question of how Germany and the European Union deal with growing immigration from the Global South, especially the Middle East, and the day-to-day business of handling the consequences of the so-called "refugee crisis" in 2015 (Krüger \& Zapf-Schramm, 2019). This topic and the way it was dealt with in the media form the background of our study.

\subsection{Immigration to Germany}

In September 2015, the German government decided to suspend the Dublin procedure for humanitarian reasons and accept several thousand refugees, mainly from Syria, who were stranded on the Balkan route between Hungary and Austria (Kumbruck, Dulle \& Vogt, 2020). As a result, 2015 became the year with the highest immigration to Germany since 1992 and a historic high for asylum applications (more than 475,000; Bundesamt für Migration und Flüchtlinge, 2016). As evidenced by the constantly high immigration figures, especially from other EU countries, resulting from the free movement of persons and the arrival of skilled workers from countries outside the EU, these events have permanently changed immigration patterns and the population structure in Germany compared to the situation at the beginning of the new millennium.

In 2019, around 21 million inhabitants in Germany had a so-called "migration background"- a term initially used in official statistics for people who immigrated or whose parent(s) immigrated to Germany and now also used in everyday language. This is around a quarter of the total population of the country. The largest migrant group historically stems from people from Turkey (about 3 million), followed by people with Polish (about 2 million) and Russian roots (about 1.4 million). In sum, about 10 million persons with migration backgrounds have German 
citizenship. In contrast, the countries of origin of people who have immigrated during the last five years highlight the change in migration patterns in Europe: Romania is in first place with a net immigration of 46,000 people, followed by Syria, India, Bulgaria, and Turkey in fifth place (Sachverständigenrat für Integration und Migration, 2021, data from 2019).

\subsection{Immigration as a topic in media coverage and online discussions}

The portrayal of immigration and immigrants in the media was an active field of research in media and communication studies even before 2015. Negativism, marginalization, and stereotypical portrayals of ethnic minorities were and continue to be empirically described characteristics of reporting in conventional mass media in Western countries (Trebbe et al., 2017). However, the sharp rise in refugee migration and an increasing shift of public debates to social media have fundamentally changed the object of research. The management of immigration by the federal government and administrative authorities has become central both to the media and the public agenda (Berry, Garcia-Blanco \& Moore, 2015; Arlt, Schumann \& Wolling, 2020). Right-wing extremist websites and social media outlets have exacerbated the tone and led to the growing polarization of social groups in many areas (Ben-David \& Matamoros-Fernandez, 2016). In Germany, mistrust of the coverage in conventional mass media on immigration has grown (Arlt \& Wolling, 2016). Marked as fake news, media outlets have become targets of hate speech themselves.

In a comparative study on the media coverage on refuge and immigration in 17 countries, the authors note that in Germany (and Hungary), the topic is particularly salient in the media. Moreover, the media coverage in Germany is comparatively undifferentiated with regard to refuge and immigration motives and origins, and the share of official and administrative actors and spokespersons is particularly high compared to opposition voices and civil society actors (Fengler $\&$ Kreutler, 2020). 
Against this background, the topic of immigration, refuge, and asylum is - as cynical as this may sound - well suited for our research aim to understand hate speech in user comments in comment sections, discussion forums, and social media. The specific characteristics of news on this issue can affect commenting behavior and quality (Ziegele et al., 2020). Due to the high values of news and discussion factors, articles and social media posts on immigration are prone to produce heated discussions and disputes in comment sections and discussion forums. The topic is socially controversial, can be instrumentalized by extremists, and has a strong polarizing effect in the public discourse. In other words, it is a fertile field for the investigation of escalating communication.

\section{Hate speech, offensive language, and user comments}

Communication research is increasingly devoted to norm-transgressing communication and hate speech in social media, with a particular increase in publications on hate speech since 2013 (Paz, Montero-Díaz \& Moreno-Delgado, 2020: pp. 3-4). While racism, anti-Semitism, or sexism are not new phenomena, such forms of group-related enmity are increasingly present in social media, where they are amplified but also take new forms (Matamoros-Fernández, 2017). Thus, Paz, Montero-Díaz and Moreno-Delgado (2020) emphasize the central role of communication studies in providing a comprehensive understanding of hate speech as communication (p. 2).

\subsection{What is hate speech?}

Originally, the term "hate speech" was coined in the legal context by critical race theorist Matsuda (1989), among others, who called for legal sanctions of racist speech targeting "historically oppressed" groups (p. 2357). It has later been linked to theories of intergroup communication and social identity theory (Leets \& Giles, 2016; Waltman \& Mattheis, 2017), which conceptualize hate speech as harmful intergroup communication that typically attacks disadvantaged and 
marginalized groups (Frischlich, 2021). Accordingly, most hate speech definitions include a group reference, but the scope of this reference varies. In contrast to Matsuda's (1989) narrow definition, other definitions include lists of specific group characteristics, such as race, ethnicity, religion, gender, gender identity, or sexual orientation (e.g., Waltman \& Mattheis, 2017: p. 2), or include all possible groups (e.g., Bahador \& Kerchner, 2019).

Moreover, since hate speech is defined to different ends, the definitions emphasize different elements of the phenomenon to varying degrees and can broadly be differentiated into three strands: 1) approaches that emphasize the intention behind hate speech to cause harm, 2) approaches that address the potential harms of hate speech, and 3) approaches that focus on the content level and attempt to define hate speech by certain content characteristics (Sellars, 2016: pp. 14-18). In order to avoid assumptions about the intentions and perceptions of individuals, it has been argued that content-based definitions are most appropriate for hate speech detection in the context of text analysis (Saleem et al., 2017).

Nonetheless, content-based definitions differ in how broadly and nuanced they define hate speech. For example, Lingiardi et al. (2020) use a lexicon-based approach and a list containing 76 insults and derogatory terms to identify hate speech targeting various groups. While such approaches help to classify content on a large scale, they fail to identify forms of hate speech that use rational or coded language. Bahador and Kerchner (2019) advocated for a more differentiated view of hate speech and developed a hate speech intensity scale ranging from 1) statements of disagreement, 2) negative actions, 3) negative characterization and insults, 4) demonizing/dehumanization, 5) rhetoric of violence to 6) rhetoric of killing associated with a target group.

Against this background, our study is based on a content-related understanding of hate speech. To avoid assumptions about the intentions of the speaker or possible consequences of a 
given statement, we argue in favor of the origins of the hate speech term and focus on discriminatory content and references to violence and killing (see section 4.2 for details).

\subsection{Hate speech and offensive language in social media}

It is difficult to find robust answers to the question of how prevalent hate speech is on the Internet, and empirical results regarding this question vary considerably due to methodological, definitional, and sampling choices. For example, in a study by Davidson, Bhattacharya, and Weber (2019), 5\% of a corpus of English-language tweets contained hate speech, while in another study also using data from Twitter, around $12 \%$ of all tweets were labeled as hate speech (Burnap \& Williams, 2015). Su et al. (2018) showed that the degree of incivility in user comments on the Facebook pages of different U.S. news outlets varied with the type of news. For example, extreme incivility was more likely to occur on local and conservative news pages (p. 13).

Another study demonstrated that organizational and country-level factors are relevant for the prevalence of hostility in user comments (Humprecht, Hellmueller \& Lischka, 2020). The authors found significantly higher levels of hostile emotions in comments on Facebook pages from U.S. news organizations compared to comments on Facebook pages of German media - a finding they attributed to a more pronounced audience polarization in the U.S. compared to Germany (pp. 3-4). However, the study also showed that German commenters attacked immigrants more often than American commenters and that hostility in the German sub-sample increased in polarized debates, for example, in discussions on immigration and on right-wing Facebook pages (p. 6).

Using a lexicon-based approach to identify hate speech against six target groups in Italian language tweets, Lingiardi et al. (2020) found that immigrants were the second most insulted group. A study on English language posts from Whisper and Twitter using sentence structure and keyword lists showed that race was the most common hate target on Twitter: out of all tweets 
containing hate speech in the sample, almost 50\% were racist (Mondal, Silva \& Benevenuto, 2017: p. 89). While both studies did not account for implicit or coded forms of hate speech, they highlighted the specific out-groups and cleavages in the public discourse of these countries.

In order to map the public debate on refugees in different European countries, Kreis (2017) conducted a critical discourse analysis of 100 tweets in four languages (English, German, Spanish, and French) using the hashtag \#refugeesnotwelcome in September 2015. In this corpus, refugees were referred to using ironic quotations marks (such as "the so-called 'refugees") to negate their legal status and devalue them. Moreover, the sampled tweets made a clear distinction between inand out-groups and framed refugees as criminals or threats (pp. 506-510), confirming the findings on typical narratives and rhetoric in the discourse of white supremacists (e.g., Waltman \& Mattheis, 2017). Kreis (2017) further showed that people supporting refugees were also targeted as out-group members and that mainstream media was accused of being biased (pp. 507-509).

There are valid arguments that the characteristics of social media create a new quality of hate. For example, Johnson et al. (2019) claim that the Internet enables "hate clusters" to organize as a global, inter-connected network that transcends platforms, languages, and "hate narratives," making them resilient and dynamic (p. 2). In addition, observers emphasize that extremist groups skillfully use the potential of new media for their goals. A study on the diffusion dynamics in Gab, a low-regulated social media platform similar to Twitter, substantiated this impression by noting that "the posts made by hateful users tend to spread farther, faster, and wider" (Mathew et al., 2019: p. 181) compared to content by other users. The study also showed that these "hateful users" were more densely connected and generated a volume of content, the proportion of which far exceeded the proportion of all such users (p. 181).

However, Matamoros-Fernández (2017) argue that social media platforms are not only "amplifiers" but also "manufacturers" of racism since racist discourse is shaped by means of their 
affordances, design, policies, and algorithmic logic. In a case study, the author exemplified how, for example, the platforms' policies to protect humor "contributed to the circulation of overt racist memes, videos and racist comments" or how Twitter's sensitive media filter was used "to disguise hate speech" (p. 949). Ben-David and Matamoros-Fernández (2016) emphasize that hate on social media can be expressed as overt hate speech but also as covert discriminatory practices that are created by the policies and affordances of the platforms and that "are prevalent, untargeted, and undetected" (p. 1188).

Springer, Engelmann, and Pfaffinger (2015) argue that user discussions in a journalistic context have the potential to enhance democratic deliberation, as diverse perspectives can be brought to the table. However, some studies suggest that these participatory spaces are also used purposely for the dissemination of discriminatory ideas. In a quantitative content analysis of articles and comments posted on U.S. news sites, Harlow (2015) showed that user comments included racial terms even if the news items did not, indicating that users have internalized stereotypes and are racially reframing journalistic topics (pp. 31-33). In a qualitative analysis of user comments on Slovenian news sites, the authors identified several strategies used by commenters to reframe the journalistic topic in an extremely polarizing way and in a sense, to justify hate speech against "the other side" (Erjavec \& Kovačič, 2012: pp. 906-908).

In summary, research has provided a variety of definitions of hate speech and empirical findings on its prevalence in different contexts. However, most studies are not comparable as they lack a common understanding and operationalization of the relevant concepts. Approaches range from big data studies that measure hate speech using keyword searches to qualitative discourse analyses of a single Twitter hashtag. 


\section{Method}

To gain a deeper insight into hate speech and offensive language in user discussions on the Internet and at the same time systematically assess the frequency of these phenomena, we combined quantitative and qualitative methods in our study. We conducted a quantitative content analysis of user comments and applied the structured text annotation method in the context of this content analysis. This method allowed us to identify and describe hate speech in as much detail as possible by separating the sentences within a given user comment that contained hate speech or offensive language from the sentences that did not. In the following, we describe the selection of sources for this analysis (Section 4.1) and explain our hate speech definition and its operationalization for the text annotation (Section 4.2).

\subsection{Sampling and data}

To build a data basis that is as rich as possible in terms of hate speech and offensive language, we applied a two-step theoretical sampling procedure of news sites and social media channels that allow for user comments. In the first step, the selection of sources was guided by three criteria: 1) high reach, 2) relevance for the public discussion on immigration issues (i.e., a high number of user comments on this topic), and 3) a variation of discourse architectures (i.e., the technological design of the participatory spaces). Using these criteria, we built a sample containing eight news sites, three right-wing blogs, seven Facebook pages, 31 YouTube channels, and one Q\&A platform for a first preliminary study in August 2018. Following the results of this preliminary study, in the second step, we selected the sources containing the most hate speech against refugees and immigrants for the content analysis discussed in this chapter. This final sample consisted of three German news sites (Compact Magazin, Epoch Times, Focus Online), one rightwing blog (pi-news.net), four Facebook pages (FOCUS Online, The Epoch Times, WELT, Zeit 
Online), and 13 YouTube channels (ARTEde, BILD, COMPACTTV, DW Deutsch, Epoch Times Deutsch, euronews (deutsch), KenFM, Laut Gedacht, MrMarxismo, Oliver Flesch, RT Deutsch, tagesschau, Tagesschlau).

Table 1: Description of the total sample

\begin{tabular}{lcc}
\hline Sources & \multicolumn{2}{c}{ Articles and posts } \\
\cline { 2 - 3 } & Freq. $(\mathbf{n})$ & $\mathbf{\%}$ \\
\hline News sites & 90 & 51 \\
\hline Focus Online & 30 & 17 \\
Epoch Times & 30 & 17 \\
Compact & 30 & 17 \\
\hline Social networks & 88 & 49 \\
\hline Blog & 30 & 17 \\
YouTube & 29 & 16 \\
Facebook & 29 & 16 \\
\hline Total & $\mathbf{1 7 8}$ & $\mathbf{1 0 0}$ \\
\hline
\end{tabular}

Using APIs and a news spider, these sources were systematically searched in March 2019 for news articles and postings that matched a list of pre-tested terms related to immigration and refuge. We then drew a stratified sample of 178 articles and posts for the subsequent analysis, aiming for an equal number of articles and posts from each of our six source types (see Table 1). ${ }^{\mathrm{i}}$ This sampling strategy was chosen to enable comparisons between the different sources without claiming any representativeness of the corpus as a whole. We further included the first (up to 50) comments for each selected article or post in the sample, since the annotation of hate speech is resource-intensive (see Paasch-Colberg et al., 2021b, for more details on the sampling procedure and the list of search terms). 


\subsection{Coding scheme and structured text annotation}

The user comments were analyzed using the structured text annotation method. In structured text annotation, a text is examined for relevant words, sentences, or sections ("entities"), which are then selected and labeled according to predefined, standardized categories ("attributes") (Stenetorp et al., 2012). Thus, this method combines the inductive identification of relevant text segments (as in qualitative text analysis) and the assignment of codes to these text segments (as in standardized content analysis). Therefore, the classification of a given text is explicitly related to specific parts of the text.

To identify hate speech and offensive language using text annotation while simultaneously applying the quality measures of standardized content analysis, we first developed a detailed, theory-based coding scheme (see also Paasch-Colberg, et al., 2021a). The essential part of this coding scheme is a nuanced definition and operationalization of hate speech in text that is based on three key elements of hate speech that are commonly referred to in many content-based definitions, as outlined in section 3.1 above (e.g., Bahador \& Kerchner, 2009):

1) negative stereotyping (i.e., the attribution of negatively connoted characteristics, roles, or behaviors to a whole group or to individuals on the basis of their group membership; see also Trebbe et al., 2017);

2) dehumanization (i.e., statements that equate or compare humans to inanimate things, animals, or inhuman beings or characterize humans as savage or animalistic; see also Maynard \& Benesch, 2016);

3) expressions of violence, harm, or killing (i.e., statements that justify, incite, or threaten physical violence against an individual or a group).

These elements were measured independently of each other in the sense that they can, but do not necessarily have to apply simultaneously to a comment in order for it to qualify as hate 
speech. Thus, our coding scheme distinguishes between forms of hate speech using various combinations of these three elements. To account for offensive language that does not qualify as hate speech but potentially escalates online discussions, we further defined three forms of offensive language: 4) insults and slurs, 5) degrading metaphors, and 6) degrading puns.

Three trained students then annotated the user comments using the BRAT rapid annotation tool, a browser-based software for structured text annotation (Stenetorp et al., 2012), following three steps: First, they checked the initial articles and postings for thematic relevance and excluded 43 articles and posts from further analysis. The net sample thus contained 135 relevant articles or posts with 5,031 user comments (see Table 2).

Table 2: Net sample

\begin{tabular}{lrrr}
\hline Sources & Articles and Posts & User comments & Judgments \\
\hline News sites & 67 & 2,385 & 1,715 \\
\hline Focus Online & 23 & 1,014 & 725 \\
Epoch Times & 22 & 710 & 523 \\
Compact & 22 & 661 & 467 \\
\hline Social networks & 68 & 2,646 & 1,055 \\
\hline Blog & 21 & 1,014 & 454 \\
YouTube & 19 & 914 & 352 \\
Facebook & 28 & 718 & 249 \\
\hline Total & $\mathbf{1 3 5}$ & $\mathbf{5 , 0 3 1}$ & $\mathbf{2 , 7 7 0}$ \\
\hline
\end{tabular}

Second, the annotators identified all judgments of individuals or groups in the user comments and then annotated them as "entities" on a sentence level. In our coding scheme, we defined a judgment as a statement expressing an opinion or an evaluation of a person or a group by ascribing (negative or positive) characteristics, roles, or behavior to it. Such judgments were identified, 
for example, by the use of adjectives and judgmental subjectivizations, the attribution of normviolating behavior, or by association of harm. In addition, the annotators were instructed to identify implicit judgments expressed by rhetorical questions, ironic statements, or historical references. In our sample, a total of 2,770 judgments were identified (see Table 2).

Third, the judgments were further qualified by attributing standardized labels to them, as defined in the coding scheme. These labels included the direction of judgment (e.g., positive, negative), the target of judgment (e.g., politicians, journalists/media, German citizens, or refugees/immigrants), and the dimension of judgment (e.g., the culture, sexuality, or character/behavior of the target). It was further noted whether a judgment included stereotyping, a dehumanization, or an expression of violence, harm, or killing (as defined above). Finally, judgments using offensive language (i.e., insults or slurs, derogatory metaphors, or derogatory puns) were qualified as such.

The context unit for the annotation of judgments was the user comment itself, the initial article or post, and the preceding comments (i.e., the annotators were instructed to use textual references within this context to identify and qualify judgments, see Paasch-Colberg et al., 2021c, for more details on the annotation).

Before the actual annotation, the annotators were extensively trained to reliably annotate the user comments in our sample following the definitions in our coding scheme. Reliability scores were good or satisfying for the judgment dimensions (with an average Holsti value $\mathrm{r}_{\mathrm{H}}=.91$ for nine labels and individual values ranging from .76 to 1.0$)$, the judgment direction $\left(\mathrm{r}_{\mathrm{H}}=.99\right)$, the identification of violent expressions $\left(\mathrm{r}_{\mathrm{H}}=.91\right)$, dehumanization $\left(\mathrm{r}_{\mathrm{H}}=.99\right)$, and stereotyping $\left(\mathrm{r}_{\mathrm{H}}=.96\right.$ for four labels, ranging from .89 to 1.0$)$, as well as for the identification of offensive language $\left(\mathrm{r}_{\mathrm{H}}=.88\right.$ for three labels, ranging from .82 to.96). Reliability was acceptable for the identification of the target of a judgment $\left(\mathrm{r}_{\mathrm{H}}=.83\right)$ but slightly below the acceptable threshold for the identification of judgments in the comments $\left(\mathrm{r}_{\mathrm{H}}=.73\right)$. Moreover, some labels occurred very rarely in the subsample 
for the reliability test (see Paasch-Colberg et al., 2021b, for more details on the reliability test). However, other content analyses in the field have also reported borderline or unsatisfactory reliability values for some hate speech or incivility dimensions (Ross et al., 2016; Ziegele et al., 2018). In other words, consistently identifying hate speech seems to be a relatively difficult task. For our annotation study, this was especially true for the identification of judgments, since this task included the highlighting of the exact text passage that included the judgment within a comment.

\section{Results}

One advantage of our approach is that the results of the content analysis can be assessed both at the level of judgments and the level of user comments. In the following, we discuss our results primarily at the judgment level, as this perspective allows for a more detailed description of the sample. In section 5.2, however, we assess the frequency of hate speech at the level of user comments to relate our results to those of other empirical studies in the field that usually refer to the comment level.

\subsection{Negativity, offensive language, and hate speech in judgements}

Regarding the judgement level, our sample was clearly characterized by negativity: in all sources, judgments that were negative in a broader sense (i.e., that expressed a negative opinion or evaluation of a person or a group by ascribing negative characteristics, roles, or behavior to them) dominated with more than $90 \%$. Only $6 \%$ of all judgments in the sample contained positive or ambivalent evaluations of individuals or groups (see Table 3). Moreover, $40 \%$ of all judgments in the sample were not just negative in this broader sense, but also contained at least one form of offensive language as defined in our framework (see Table 4). In particular, the judgments in the blog comments were characterized by a frequent use of offensive language. In comparison, hate 
speech, as we defined and operationalized it for the purpose of our study, occurred less frequently than offensive language: overall, we identified elements of hate speech in a quarter of our study corpus $(25 \%$, see Table 5$)$.

Table 3: Percentage of judgment characteristics and sources

\begin{tabular}{lrrrrr}
\hline \multirow{2}{*}{ Judgment characteristics } & \multicolumn{4}{c}{ Source } & \multirow{2}{*}{ Total } \\
\cline { 2 - 5 } & News sites & Blog & YouTube & Facebook & \\
\cline { 2 - 5 } & $\mathrm{n}=1,715$ & $\mathrm{n}=454$ & $\mathrm{n}=352$ & $\mathrm{n}=249$ & $\mathrm{n}=2,770$ \\
\hline Positive/ambivalent & 7 & 4 & 4 & 5 & 6 \\
\hline Negative & 93 & 96 & 96 & 95 & 94 \\
\hline Negative & 48 & 28 & 46 & 65 & 46 \\
Negative and Offensive & 21 & 35 & 20 & 15 & 23 \\
Hate Speech & 10 & 9 & 12 & 7 & 10 \\
Hate Speech and Offensive & 14 & 24 & 18 & 9 & 16 \\
\hline Total & $\mathbf{1 0 0}$ & $\mathbf{1 0 0}$ & $\mathbf{1 0 0}$ & $\mathbf{1 0 0}$ & $\mathbf{1 0 0}$ \\
\hline
\end{tabular}

Examining the co-occurrences of these characteristics (i.e., negative judgment, offensive language, and hate speech), it is possible to describe the intensity of devaluation of individuals and groups in the identified judgments. Table 3 shows that nearly half of all judgments in our sample were negative (46\%), while another $23 \%$ were negative and also used offensive language. Such negative and offensive judgments were particularly frequent in blog comments (35\%). The table also reveals the extent to which hate speech and offensive language appeared together: ten percent of the judgments in our sample were classified as hate speech according to our framework but did not use any form of offensive language, while another $16 \%$ of judgments contained elements of both hate speech and offensive language. This might be an explanation for a stated underestimation of hate speech based on only abusive and offensive language (e.g., in Lingiardi et al., 2020). 
Table 4: Percentage of offensive language in judgments ${ }^{l}$

\begin{tabular}{lrrrrr}
\hline Offensive language & \multicolumn{3}{c}{ Source } & \multirow{2}{*}{ Total } \\
\cline { 2 - 5 } & News sites & Blog & YouTube & Facebook & \\
\cline { 2 - 5 } & $\mathrm{n}=1,715$ & $\mathrm{n}=454$ & $\mathrm{n}=352$ & $\mathrm{n}=249$ & $\mathrm{n}=2,770$ \\
\hline Non-offensive & 65 & 40 & 62 & 77 & 61 \\
\hline Offensive language & 35 & 60 & 38 & 23 & 39 \\
\hline Insults & 12 & 21 & 14 & 6 & 13 \\
Degrading metaphors & 11 & 14 & 14 & 6 & 11 \\
Degrading wordplays & 21 & 39 & 19 & 15 & 23 \\
\hline Total & $\mathbf{1 0 0}$ & $\mathbf{1 0 0}$ & $\mathbf{1 0 0}$ & $\mathbf{1 0 0}$ & $\mathbf{1 0 0}$ \\
\hline
\end{tabular}

${ }^{1}$ The offensive language forms are multiple responses.

Table 5: Percentage of hate speech in judgments ${ }^{1}$

\begin{tabular}{lrrrrr}
\hline Hate Speech & \multicolumn{4}{c}{ Source } & Total \\
\cline { 2 - 5 } & News sites & Blog & YouTube & Facebook & \\
\cline { 2 - 5 } & $\mathrm{n}=1,715$ & $\mathrm{n}=454$ & $\mathrm{n}=352$ & $\mathrm{n}=249$ & $\mathrm{n}=2,770$ \\
\hline No hate speech & 76 & 67 & 70 & 84 & 75 \\
\hline Hate speech & 24 & 33 & 30 & 16 & 25 \\
\hline Stereotyping & 20 & 26 & 21 & 15 & 21 \\
Dehumanization & 5 & 10 & 8 & 3 & 6 \\
Violence/Killing & 4 & 3 & 10 & - & 4 \\
\hline Total & $\mathbf{1 0 0}$ & $\mathbf{1 0 0}$ & $\mathbf{1 0 0}$ & $\mathbf{1 0 0}$ & $\mathbf{1 0 0}$ \\
\hline
\end{tabular}

${ }^{1}$ The hate speech forms are multiple responses.

Among these judgments containing hate speech, stereotypical terms and generalizations (21\%) were most prevalent (see Table 5). In comparison, the more extreme phenomena of dehumanization and threat of violence and killing were identified less frequently. However, $10 \%$ of the judgments identified in the YouTube material contained a drastic form of hate speech. The source 
with the lowest rate of hate speech judgments was Facebook: $84 \%$ of the judgments identified on Facebook did not use any form of hate speech according to our definition, while in the other sources, this value varied between $67 \%$ (the right-wing blog) and $76 \%$ (news sites overall). To be clear, referring to violence and killing as "extreme" is not necessarily an indicator of stronger effects compared to stereotyping or dehumanization. From a media effects perspective, even the opposite hypothesis can be formulated, namely that stereotyping has a greater effect potential due to its frequency and consonance (e.g., Koch \& Arendt, 2017). Nevertheless, the threat of violence and killing is a far more dangerous scenario from the individual perspective of a (potential) victim.

\subsection{The prevalence of hate speech in user comments}

To relate our findings on the prevalence of hate speech to the current state of research, we briefly switch from the judgment level to the level of user comments. Since a comment could contain multiple judgments, hate speech was less prevalent at the comment level: $12.5 \%$ of all user comments in the sample $(\mathrm{n}=630)$ contained at least one judgment that we considered to be hate speech. Compared to the studies discussed in section 3.2, this is a rather large proportion. However, this can be explained by our sampling model, which consciously included sources that were likely to have hate speech in the user comments (see Section 4.1).

\subsection{Targets of offensive language and hate speech in judgments}

In order to distinguish between different forms of hate speech, we further identified the target group of every judgment. Our data show that refugees and immigrants are clearly the focus of online discussions on the topic: about a quarter of all identified judgments refer to them. Table 6 shows two findings in particular: 1) in online discussions, this group (“out-group") in particular becomes the subject of (negative) judgments compared to most other groups and 2) when this 
group is judged by a user, these judgments often contain hate speech and/or offensive language. Even if we consider the thematic context of immigration and refuge in our sample, this finding shows the dominant focus on refugees and immigrants as targets of (negative) judgments and hate speech. In contrast, actors from politics and the media are comparatively less likely to be targets of explicit hate speech (19\% and 10\%, respectively), although negative judgments with offensive language also occur frequently for these groups.

Table 6: Percentage of targets of offensive language and hate speech

\begin{tabular}{lrrrrrrrr}
\hline & $\begin{array}{r}\text { Politi- } \\
\text { cians }\end{array}$ & $\begin{array}{r}\text { Jour- } \\
\text { nalists }\end{array}$ & $\begin{array}{r}\text { German } \\
\text { Society }\end{array}$ & $\begin{array}{r}\text { Ger- } \\
\text { mans }\end{array}$ & Islam & $\begin{array}{r}\text { Refu- } \\
\text { gees }\end{array}$ & $\begin{array}{r}\text { Unspe- } \\
\text { cific }\end{array}$ & Total \\
\cline { 2 - 8 } & $\mathrm{n}=1,272$ & $\mathrm{n}=129$ & $\mathrm{n}=135$ & $\mathrm{n}=275$ & $\mathrm{n}=74$ & $\mathrm{n}=720$ & $\mathrm{n}=165$ & $\mathrm{n}=2,770$ \\
\hline Pos./ambivalent & 8 & 11 & 4 & 7 & 8 & 3 & 1 & 6 \\
\hline Negative & 92 & 89 & 96 & 94 & 92 & 97 & 99 & 94 \\
\hline Negative (only) & 51 & 61 & 57 & 43 & 39 & 34 & 49 & 46 \\
Neg. \& Offensive & 23 & 19 & 21 & 30 & 30 & 19 & 27 & 23 \\
Hate Speech & 5 & 2 & 6 & 8 & 14 & 22 & 8 & 10 \\
HS \& Offensive & 14 & 8 & 12 & 12 & 10 & 23 & 16 & 16 \\
\hline Total & $\mathbf{1 0 0}$ & $\mathbf{1 0 0}$ & $\mathbf{1 0 0}$ & $\mathbf{1 0 0}$ & $\mathbf{1 0 0}$ & $\mathbf{1 0 0}$ & $\mathbf{1 0 0}$ & $\mathbf{1 0 0}$ \\
\hline
\end{tabular}

If we take a closer look at this phenomenon and compare politicians and refugees in terms of being targets of hate speech, we find noteworthy differences in the dimensions of judgment (see Table 7). While politicians are primarily judged in terms of general negative aspects of their behaviors and character, refugees are more often evaluated in terms of the alleged illegality of their presence or behavior. This category includes, for example, general negative statements that refugees are criminals, but also more specific accusations that they entered illegally or committed specific crimes. 
Table 7: Percentage of judgment dimensions and target groups, multiple responses ${ }^{1}$

\begin{tabular}{lrrrr}
\hline Judgment dimensions & \multicolumn{3}{c}{ Target group } & Total \\
\cline { 2 - 4 } & Politicians & Refugees & Other targets & \\
\cline { 2 - 5 } & $\mathrm{n}=230$ & $\mathrm{n}=322$ & $\mathrm{n}=149$ & $\mathrm{n}=701$ \\
\hline Health & 7 & 2 & 4 & 4 \\
Intelligence & 6 & 4 & 14 & 7 \\
Appearance & 2 & 3 & 1 & 2 \\
Character/Behavior & 58 & 36 & 47 & 46 \\
Culture & 0 & 4 & 0 & 2 \\
Sexuality & 0 & 5 & 4 & 3 \\
Lawfullness & 12 & 30 & 9 & 20 \\
Impact on Germany & 8 & 11 & 3 & 8 \\
Unspecific & 27 & 34 & 36 & 32 \\
\hline Total & $\mathbf{1 0 0}$ & $\mathbf{1 0 0}$ & $\mathbf{1 0 0}$ & $\mathbf{1 0 0}$ \\
\hline
\end{tabular}

${ }^{1}$ Percentage bases are the $n=701$ judgments with hate speech.

As findings from a large corpus of research about stigmatization and stereotyping in legacy media show, the attribution of crime, delinquent behavior, and negativity in general is a characteristic of the coverage on refuge and immigration (Trebbe et al. 2017). Against this backdrop and in line with Kreis (2017), our results point to major parallels between legacy media reporting and user comments on social media. However, as the findings of Harlow (2015) and Erjavec and Kovačič (2012) show, the comment sections are also used-at least by some-to (consciously or unconsciously) reframe journalistic topics and frames. These tendencies might increase polarization and cleavages between different user groups.

\section{Discussion and conclusion}

In this chapter, we focused on negative evaluations and the manifestations of hate speech in public discourse on migration and refuge, which has been strongly influenced by right-wing populist, 
racist, and Islamophobic positions in the last decade. Our aim was to gain detailed insight into the forms of hate speech in German comment sections on the Internet and in social media, while also accounting for forms of offensive language that do not qualify as hate speech.

By combining quantitative and qualitative methods, our annotation-based content analysis provides results that transcend a "hate/no-hate" dichotomy and an analysis of extreme or blatant hate speech forms. Three findings seem particularly noteworthy to us, regarding their possible consequences for public discourse on immigration in Germany and the potential threat they pose for especially vulnerable groups. First, negativity was a central feature of online user comments in the area of our study: The vast majority of identified judgments in our sample were negative, $40 \%$ used offensive language, and one in four judgements contained at least one hate speech element. Positive evaluations of individuals and groups, on the contrary, were very unlikely. This result confirms the finding that the topic of migration is currently being discussed particularly aggressively in participatory spaces in Germany (see also Humprecht, Hellmueller \& Lischka, 2020).

Second, notable differences between the platforms became apparent. On Facebook, about two-thirds of the negative judgments were, based on their wording, neither offensive nor characterized by explicit hate speech. In contrast, about two-thirds of the judgments we identified in the user comments posted on the blog selected for our sample used either offensive language or hate speech, and $10 \%$ of the YouTube judgments contained extreme forms of hate speech (i.e., violence or killing). This, however, was partly due to our sampling strategy, which led us more or less to select right-wing blogs with a high probability of containing offensive attitudes against migrants and state and civil society actors. Nevertheless, this finding proves the importance and potential danger of these blogs with respect to the dissemination of discriminatory and hostile narratives.

Third, our results showed a particular focus on immigrants and refugees in online hate speech: in terms of frequency, this group was primarily the target of hate speech in user comments 
on immigration to Germany, while other groups were targeted less frequently. In addition, hate speech targeting immigrants and refugees often (falsely) attributed criminal behavior to them and, thus, framed them as a danger. While this pattern of attribution in user comments resembles the familiar "syndromes" of legacy media coverage on refugees and migrants (see Section 2.2), it illustrates the particular potential dangers of hate speech targeting migrants and refugees in Germany. It can be assumed that this blend of the strong criminalization of refugees and migrants and misinformation makes hate speech against this group particularly dangerous.

We do not claim our sample to be representative of the German social media or online public sphere in general. In particular, the sampling procedure favored the inclusion of pages and accounts with a higher probability of offensive and hateful postings. However, with the sampling approach, we tried to cover all relevant spheres of the online public-media comment sections, social media platforms, and independent blogs and websites. Thus, it can provide relevant insights into the characteristics of hate speech and offensive language in online discussions on an important political and social issue. It would not only be interesting but also imperative to expand the range of topics and media in order to promote systematic insights into the role and nature of hate speech and offensive language in public discussions on other topics and media.

\section{References}

Arlt D, Schumann C, Wolling J (2020) Upset with the refugee policy: Exploring the relations between policy malaise, media use, trust in news media, and issue fatigue. Communications. 45(s1): 624-647. https://doi.org/10.1515/commun-2019-0110

Arlt D, Wolling J (2016) The refugees: Threatening or beneficial? Exploring the effects of positive and negative attitudes and communication on hostile media perceptions. Global Media Journal - German. 6(1): 1-21. https://nbn-resolving.org/urn:nbn:de:gbv:547-201600309 
Bachl M (2018) (Alternative) media sources in AfD-centered Facebook discussions. Studies in Communication and Media. 7(2): 256-270. https://doi.org/10.5771/2192-4007-2018-2-128

Bahador B, Kerchner D (2019) Monitoring hate speech in the US media (Working Paper). https://mediapeaceproject.smpa.gwu.edu/report/

Ben-David A, Matamoros-Fernández A (2016) Hate speech and covert discrimination on social media: Monitoring the Facebook pages of extreme-right political parties in Spain. International Journal of Communication. 10: 1167-1193. https://ijoc.org/index.php/ijoc/arti$\underline{\text { cle/view/3697 }}$

Berbuir N, Lewandowsky M, Siri J (2015) The AfD and its sympathisers: Finally a right-wing populist movement in Germany? German Politics. 24(2): 154-178.

https://doi.org/10.1080/09644008.2014.982546

Berry M, Garcia-Blanco I, Moore K (2015) Press coverage of the refugee and migrant crisis in the EU: A content analysis of five European countries. Report prepared for the United Nations High Commissioner for Refugees. https://www.unhcr.org/56bb369c9.pdf

Bundesamt für Migration und Flüchtlinge (2016) Migration Report 2015 [Migrationsbericht 2015]. Berlin, Nürnberg. https://www.bamf.de/SharedDocs/Anlagen/DE/Forschung/Migrationsberichte/migrationsbericht-2015.pdf

Burnap P, Williams ML (2015) Cyber hate speech on Twitter: An application of machine classification and statistical modeling for policy and decision making. Policy \& Internet. 7(2): 223-242. https://doi.org/10.1002/poi3.85

Davidson T, Bhattacharya D, Weber I (2019) Racial bias in hate speech and abusive language detection datasets. In: $A L W 3,3 r d$ Workshop on abusive language online. https://arxiv.org/abs/1905.12516 
Erjavec K, Kovačič MP (2012) "You don't understand, this is a new war!" Analysis of hate speech in news web sites' comments. Mass Communication and Society. 15(6): 899-920. https://doi.org/10.1080/15205436.2011.619679

Fengler S, Kreutler M (2020) Migration coverage in Europe's media. A comparative analysis of coverage in 17 countries. OBS Working paper 39. Frankfurt (Main), Otto-BrennerStiftung. Available from: https://www.otto-brenner-stiftung.de/fileadmin/user_data/stiftung/02_Wissenschaftsportal/03_Publikationen/AP39_Migration_EN.pdf

Frischlich, L (2021, in Press) Hate and harm. In: Strippel C, Paasch-Colberg S, Emmer M, Trebbe J (eds) Challenges and perspectives of hate speech analysis. Berlin, Digital Communication Research.

Frischlich L, Klapproth J, Brinkschulte F (2020) Between mainstream and alternative. Co-orientation in right-wing populist alternative news media. In: Grimme C, Preuss M, Takes FW, Waldherr A (eds.) Disinformation in open online media. Springer, pp 150-167.

Gehrke L (May 4, 2021) Germany records highest level of right-wing extremist crime in 20 years. Politico. https://www.politico.eu/article/germany-records-highest-level-of-rightwing-extremist-crimes-in-20-years/

Harlow S (2015) Story-chatterers stirring up hate: Racist discourse in reader comments on U.S. newspaper websites. Howard Journal of Communications. 26(1): 21-42. https://doi.org/10.1080/10646175.2014.984795

Humprecht E, Hellmueller L, Lischka JA (2020) Hostile emotions in news comments: A crossnational analysis of Facebook discussions. Social Media + Society. 6(1): 1-12. https://doi.org/10.1177\%2F2056305120912481 
Johnson NF, Leahy R, Johnson Restrepo N, Velasquez N, Zheng M, Manrique P, Devkota P, Wuchty S (2019) Hidden resilience and adaptive dynamics of the global online hate ecology. Nature. 573: 261-265. https://doi.org/10.1038/s41586-019-1494-7

Koch T, Arendt F (2017). Media effects: Cumulation and duration. In: Rössler P, Hoffner CA, Zoonen L (eds). The International Encyclopedia of Media Effects, pp 1-11. https://doi.org/10.1002/9781118783764.wbieme0217

Krämer B (2016) Populist online practices: The function of the Internet in right-wing populism. Information, Communication \& Society. 20(9): 1293-1309. https://doi.org/10.1080/1369118X.2017.1328520

Kreis R (2017) \#refugeesnotwelcome: Anti-refugee discourse on Twitter. Discourse \& Communication. 11(5): 498-514. https://doi.org/10.1177/1750481317714121

Krüger UM, Zapf-Schramm T (2019) InfoMonitor 2018: Grand coalition and migration debate dominate the television news. Analysis of the news programmes of Das Erste, ZDF, RTL and Sat.1 [InfoMonitor 2018: GroKo und Migrationsdebatte prägen die Fernsehnachrichten. Analyse der Nachrichtensendungen von Das Erste, ZDF, RTL und Sat.1]. Media Perspektiven. 2019(2): 44-73. https://www.ard-werbung.de/fileadmin/user_upload/media-perspektiven/pdf/2019/0219_Krueger_Zapf-Schramm_2019-02-13.pdf

Kumbruck C, Dulle M, Vogt M (2020) Controversial refugee admission. Insights into the thinking and activities of committed people [Flüchtlingsaufnahme kontrovers, Einblicke in die Denkwelten und Tätigkeiten von Engagierten]. Baden-Baden, Nomos.

Leets L, Giles H (2016) Harmful speech in intergroup encounters: An organizational framework for communication research. Annals of the International Communication Association. 22(1): 91-137. https://doi.org/10.1080/23808985.1999.11678960 
Lingiardi V, Carone N, Semeraro G, Musto C, D’Amico M, Brena S (2020) Mapping Twitter hate speech towards social and sexual minorities: A lexicon-based approach to semantic content analysis. Behaviour \& Information Technology. 39(7): 711-721.

https://doi.org/10.1080/0144929X.2019.1607903

Matamoros-Fernández A (2017) Platformed racism: The mediation and circulation of an Australian race-based controversy on Twitter, Facebook and YouTube. Information, Communication \& Society. 20(6): 930-946. https://doi.org/10.1080/1369118X.2017.1293130

Mathew B, Dutt R, Goyal P, Mukherjee A (2019) Spread of hate speech in online social media. Proceedings of the 10th ACM Conference on Web Science. https://doi.org/10.1145/3292522.3326034

Matsuda M (1989) Public response to racist speech: Considering the victim's story. Michigan Law Review, 87(8): 2320-2381. https://doi.org/10.2307/1289306

Leader Maynard J, Benesch S (2016) Dangerous speech and dangerous ideology: An integrated model for monitoring and prevention. Genocide Studies and Prevention. 9(3): 70-95. http://dx.doi.org/10.5038/1911-9933.9.3.1317

Mondal M, Silva LA, Benevenuto F (2017). A measurement study of hate speech in social media. In: HT'17 - Proceedings of the 28th ACM Conference on Hypertext and Social Media. https://doi.org/10.1145/3078714.3078723

Paasch-Colberg S, Strippel C, Emmer M, Trebbe J (2021a) From insult to hate speech: Mapping offensive language in German user comments on immigration. Media and Communication. 9(1): 171-180. https://doi.org/10.17645/mac.v9i1.3399

Paasch-Colberg S, Strippel C, Laugwitz L, Emmer M, \& Trebbe J (2021b) Field Report: Hate Speech on the Internet 3/2019-Annotation-based content analysis of user comments on the 
topic of refuge and immigration posted in March 2019 (Methods report) [Field Report: Hate Speech im Internet 3/2019 - Annotationsbasierte Inhaltsanalyse von Nutzerkommentaren zum Thema Flucht und Migration aus März 2019 (Methodenbericht)]. https://doi.org/10.31235/osf.io/7n45g

Paasch-Colberg S, Strippel C, Laugwitz L, Emmer M, \& Trebbe J (2021c). Codebook: Hate Speech on the Internet 03/2019-Annotation-based content analysis of user comments on the topic of refuge and immigration posted in March 2019 (Codebook) [Codebuch: Hate Speech im Internet 3/2019 - Annotationsbasierte Inhaltsanalyse von Nutzerkommentaren zum Thema Flucht und Migration aus März 2019 (Codebuch)]. https://doi.org/10.31235/osf.io/c59kn

Paz MA, Montero-Díaz J, Moreno-Delgado A (2020) Hate speech: A systematized review. SAGE Open. 10(4). https://doi.org/10.1177/2158244020973022

Puschmann C, Ausserhofer J, Maan N, Hametner M (2016) Information laundering and counterpublics: The news sources of islamophobic groups on Twitter. Proceedings of the International AAAI Conference on Web and Social Media, 10(1). https://ojs.aaai.org/index.php/ICWSM/article/view/14847

Rauchfleisch A, Kaiser J (2020) The German far-right on YouTube: An analysis of user overlap and user comments. Journal of Broadcasting \& Electronic Media. 64(3): 373-396. https://doi.org/10.1080/08838151.2020.1799690

Ross B, Rist M, Carbonell G, Cabrera B, Kurowsky N, Wojatzki M (2016) Measuring the reliability of hate speech annotations: The case of the European refugee crisis. NLP4CMC III, $3 r d$ Workshop on Natural Language Processing for Computer-Mediated Communication. Bochum. https://doi.org/10.17185/duepublico/42132 
Sachverständigenrat für Integration und Migration (2021) Facts on immigration to Germany [Fakten zur Einwanderung in Deutschland].

https://www.svr-migration.de/wp-content/uploads/2021/02/SVR-Fakten-zurEinwanderung.pdf

Saleem HM, Dillon KP, Benesch S, Ruths D (2017) A web of hate: Tackling hateful speech in online social spaces. Paper presented at the first Workshop on Text Analytics for Cybersecurity and Online Safety (TA-COS), Portorož. https://arxiv.org/abs/1709.10159

Sellars A (2016) Defining hate speech (Research publication No. 2016-20). Cambridge, MA, Berkman Klein Center. https://doi.org/10.2139/ssrn.2882244

Springer N, Engelmann I, Pfaffinger C (2015) User comments: motives and inhibitors to write and read. Information, Communication \& Society. 18(7): 798-815. https://doi.org/10.1080/1369118X.2014.997268

Stenetorp P, Pyysalo S, Topic G, Ohta T, Ananiadou S, Tsujii JI (2012) BRAT: A web-based tool for NLP-assisted text annotation. The Demonstrations at the 13th Conference of the European Chapter of the Association for Computational Linguistics. Avignon, France. https://www.aclweb.org/anthology/E12-2021

Stier S, Posch L, Bleier A, Strohmaier M (2020) When populists become popular: Comparing Facebook use by the right-wing movement Pegida and German political parties. Information, Communication \& Society. 29(9): 1365-1388.

https://doi.org/10.1080/1369118X.2017.1328519

Su LYF, Xenos MA, Rose KM, Wirz C, Scheufele DA, Brossard D (2018) Uncivil and personal? Comparing patterns of incivility in comments on the Facebook pages of news outlets. New Media \& Society. 201(10): 3678-3699. https://doi.org/10.1177/1461444818757205 
Toepfl F, Piwoni E (2015) Public spheres in interaction: Comment sections of news websites as counterpublic spaces. Journal of Communication. 65(3): 465-488.

https://doi.org/10.1111/jcom.12156

Trebbe J, Paasch-Colberg S, Greyer J, Fehr A (2017) Media representation: Racial and ethnic stereotypes. In: Rössler P (ed) The international encyclopedia of media effects. Hoboken, NJ, John Wiley \& Sons.

Waltman MS, Mattheis AA (2017) Understanding hate speech. In Oxford Research Encyclopedia of Communication. New York, NY, Oxford University Press. https://doi.org/10.1093/acrefore/9780190228613.013.422

Weber P (2014) Discussions in the comments section: Factors influencing participation and interactivity in online newspapers' reader comments. New Media \& Society. 16(6): 941-957. https://doi.org/10.1177/1461444813495165

Wegner J, Prommer E, Seidel CC (2020) Free speech under pressure: The effect of online harassment on literary writers. Media and Communication. 8(4): 145-157.

https://doi.org/10.17645/mac.v8i4.3252

Ziegele M, Quiring O, Esau K, Friess D (2020). Linking news value theory with online deliberation: How news factors and illustration factors in news articles affect the deliberative quality of user discussions in SNS' comment sections. Communication Research. 47(6): 860890. https://doi.org/10.1177/0093650218797884

Ziegele M, Jost P, Bormann M, Heinbach D (2018) Journalistic counter-voices in comment sections: Patterns, determinants, and potential consequences of interactive moderation of uncivil user comments. Studies in Communication and Media. 7(4): 525-554.

https://doi.org/10.5771/2192-4007-2018-4-525 
Acknowledgements: This research is part of the project "NOHATE-Overcoming crises in public communication about refugees, migration, foreigners," funded by the German Federal Ministry of Education and Research (grant number 01UG1735AX).

The intended stratification of the sample with 30 cases from each source was realized with the exception of YouTube and Facebook, where only 29 postings were found during March 2019 using our search terms. 